\title{
On the relationship between local stresses and strains in Arctic pack ice
}

\author{
W. B. Tucker, in And D. K. Perovich \\ US Army Cold Regions Research and Engineering Laboratory, 72 Lyme Road, Hanover, NH 03755, U.S.A. \\ M. A. Hopkins And W. D. HibleR, III \\ Thayer School of Engineering, Dartmouth College, Hanover, NH 03755, U.S.A.
}

\begin{abstract}
Local ice strains and in situ ice stresses were simultaneously measured on the Coordinated Eastern Arctic Experiment (CEAREX). The experiment took place in the fall of 1988 and was centered about an ice-strengthened ship moored to a multi-year floe in the pack ice northeast of Spitsbergen. During the period of data collection, which extended from early October to late November, the ship and the ice surrounding it drifted from $82^{\circ} 40^{\prime} \mathrm{N}, 32^{\circ} 32^{\prime} \mathrm{E}$ to $78^{\circ} 54^{\prime} \mathrm{N}, 31^{\circ} 27^{\prime} \mathrm{E}$.

As soon as ice temperatures were low enough to permit installation, stress sensors were placed at four sites, two sites on each of two adjacent multi-year floes. Principal stress components and the principal stress direction were determined at each sensor. At the same time, microwave transponders, capable of measuring ice deformation to accuracies better than $1 \mathrm{~m}$, were positioned within $1 \mathrm{~km}$ of the stress sensors and provided an approximation of the local strain field.

What makes this joint dataset particularly interesting is that it includes some large ridging events and a particularly large event which terminated the experiment when the multi-year floes in the local area were broken into small fragments. A wide range of ice stresses was measured during the period. The largest compressive stresses, about $250 \mathrm{kPa}$, were measured by the near-surface sensors. Although sensors in different locations responded differently to ice movement, the large events were common to all shallow sensors.
\end{abstract}

\section{INTRODUGTION}

Knowing the magnitude of in situ ice forces is essential for properly quantifying the geophysical-scale ice strength, as well as for engineering applications such as calculating loads on structures. It is generally recognized that the maximum sustainable stresses in pack ice are largely a function of the forces involved in the formation of pressure ridges. There are few measurements of these forces, however. Estimates of ridge-building forces by different investigators vary by over an order of magnitude (Croasdale and others, 1988), clearly indicating the need to measure stresses during deformation events.

The petroleum industry has sponsored measurements of ice forces in the vicinity of offshore structures, with the primary intent being to define local ice pressures on the structure (e.g. Graham and others, 1983; Hawkins and others, 1983). As a result of these efforts, the technology for measuring ice stresses has been greatly advanced, and sensors now exist that are capable of resolving in situ packice stresses. Also, modeling studies of stress distributions in ar. 2 Hoe as a result of ridge-building forces exerted on the perimeter of the floe are providing valuable insight in the determination of the optimum locations for installing stress sensors (Frederking and Evgin, 1990).

Two recent efforts attempted to measure spatially averaged pack-ice forces by implanting sensors in the centers of large multi-year floes. Croasdale and others (1988) installed two types of sensors, which included strain gauged disk and hydraulic flatjack designs, in a floe in the Beaufort Sea. A primary purpose of the experiment was to evaluate sensors and installation techniques. A ridging event was experienced during the program, and surprisingly, the largest compressive stress measured was only about $20 \mathrm{kPa}$. Drawing on this experience, Comfort and Ritch (1990) obtained a more extensive set of measurements, also in the Beaufort Sea. Again, the strain gauged disk and hydraulic flatjack types of sensors were employed, and more effort was invested in examining the horizontal and vertical distribution of stresses in the floe. Ridging also occurred during this experiment, and a $190 \mathrm{kPa}$ stress increase was recorded by one sensor. Both of these efforts obtained interesting and useful results, although significant questions remain regarding sensor capabilities and the distribution of stresses within the ice.

The investigation described here concerns ice stress 


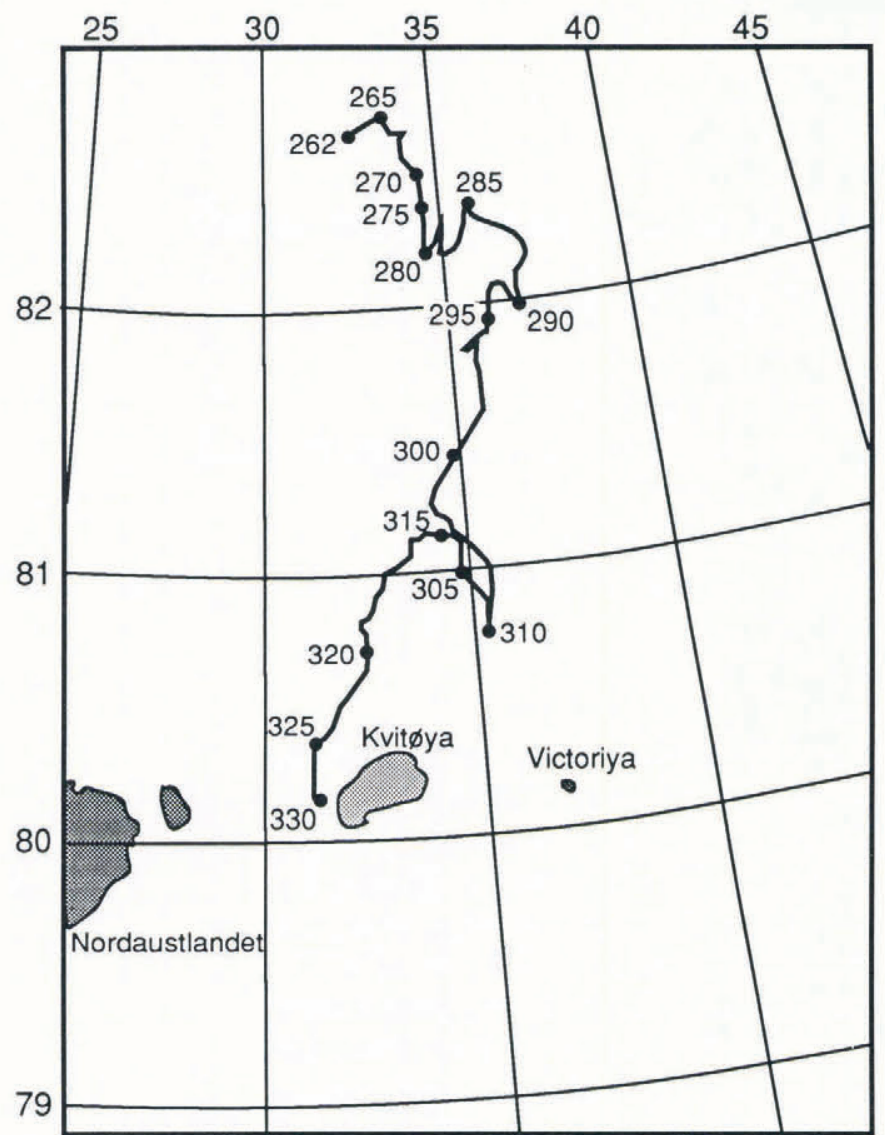

Fig. 1. Drift track of the Polarbjorn from day 262 to 330.

measurements that were made recently in the eastern Arctic. One component of the Coordinated Eastern Arctic Experiment (CEAREX) was a drift phase in which the research vessel Polarbjorn was moored to a large multi-year floe and allowed to drift with the pack from midSeptember until late November 1988, when extreme deformation caused the disintegration of all large floes in the local area. The drift track of the floe (and ship) is shown in Figure 1 for the drift period which began on 18 September 1988 (day 262) and ended on 25 November 1988 (day 330). A complete suite of ice, meteorological and oceanographic measurements was conducted during the drift. To complement the ice stress measurements, the local ice deformation was monitored. The intent was to measure the motion of floes surrounding those on which stress sensors were installed, so that events of divergence, convergence and ridging could be quantitatively determined.

\section{INSTRUMENTATION}

\section{Strain measurements}

A microwave transponder system manufactured by Del Norte Technology, Inc. was used to measure the local ice displacement. The same system (although since modified) has been used for measuring displacements of nearshore ice in the Alaskan Beaufort Sea (Tucker and others, 1980) and in the Fram Strait marginal ice zone (Leppäranta and Hibler, 1987). The system consisted of two master transponder units defining the base line and five remote units at points in the nearby ice pack surrounding the Polarbjorn. The positions of the remote units with respect to the base line were determined with $\pm 1 \mathrm{~m}$ accuracy at 2 min time intervals from Julian Day 282 until 320. After day 320 we continued to measure deformations from a single master unit located on the ship. The temperature drift of the transponders was removed using a linear correction obtained from a least-squares analysis of deformation versus air temperature.

Because of logistical constraints, the arrangement of remote transponders in the local ice pack about the Polarbjorn was such that the number of lines of deformation measured for the determination of a formal strain field was minimal. We were able to fix the positions of four points in the near field. These positions allowed us to establish two strain triangles. Due to the small scale of the area of measurement, the strain field defined by a triangle tended to be discontinuous. For example, the motion of one of the points of the first triangle (the rightmost in Figure 2) was characterized by ridging and opening perpendicular to the line of deformation at a point close to the remote transponder. Similarly, the motion of one of the points of the second strain triangle (the leftmost in Figure 2) was characterized by extreme shear perpendicular to the line at a point beyond Beta floe. The ice near the ship, in the vicinity of the stress sites, was relatively motionless during the ridging and shear events which affected the triangles. In addition, several of the lines of deformation were nearly colinear over much of the experiment. Therefore, in order to close the strain triangles, the third leg between two of the remotes had to be synthesized. This necessitated a great deal of smoothing in order to obtain a reasonably accurate strain field.

One might expect the strains in the near field to be felt in the ice at the stress sites. However, there is very little
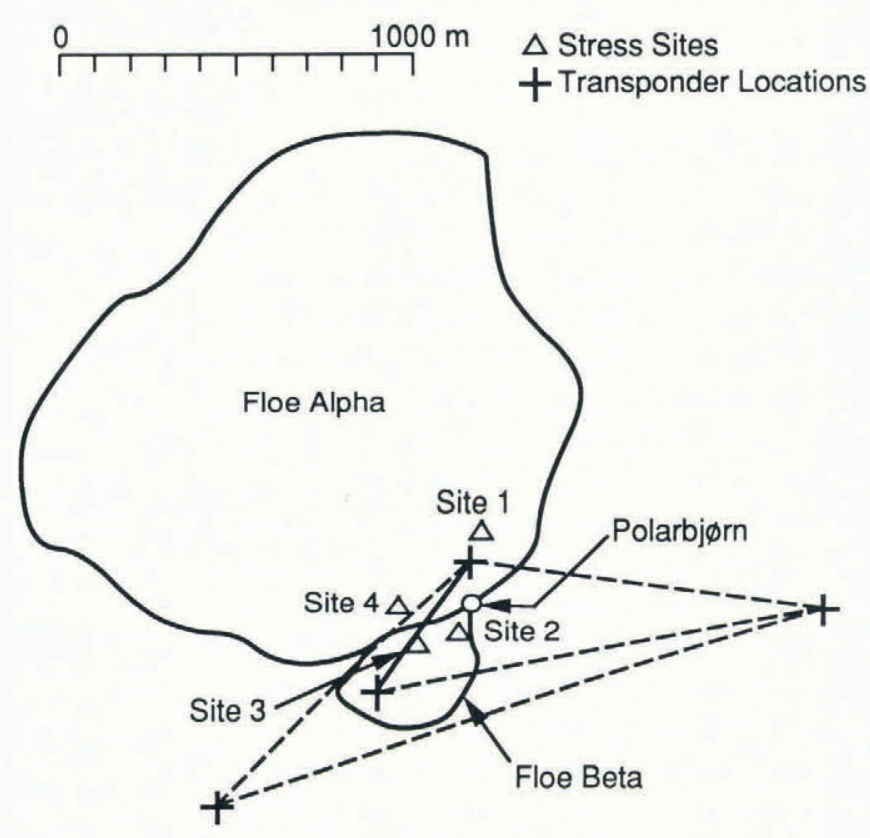

Fig. 2. Schematic diagram of Alpha and Beta floes illustrating the locations of the stress sensor sites and the Del Norte transponder locations. The dashed lines define the strain triangles; the solid line is leg 1, which was used for the deformation analysis. 
correlation between the measured stresses and the strain fields determined from the deformation of the two triangles. In fact, as a result of the very discontinuous motion in the near pack, the strain fields themselves are very different. Therefore, for comparison with the stress measurements, we have chosen to focus on the motion of a single line of deformation (leg 1 in Figure 2) from the ship to a remote transponder located near the stress site on Beta floe.

\section{Stress measurements}

Biaxial vibrating wire sensors were used to measure the stresses described here. The sensor consists of a stiff steel sensor, $6 \mathrm{~cm}$ in diameter and $25 \mathrm{~cm}$ long. Inside the cylinder, six tensioned wires are set at $30^{\circ}$ intervals across the diameter. Only three wires separated by angles of $60^{\circ}$ are necessary to resolve the principal stress components; the remaining three wires serve as spares. The principal stresses in the plane of the wires (the horizontal plane of the ice) are determined by the radial deformation of the cylinder. Deformation in the direction of each wire is determined by the resonant frequency of each wire after it has been plucked by a magnet/coil assembly. Cox and Johnson (1983) present the theory and methods of obtaining principal ice stress components from the sensors. They also describe extensive laboratory tests using saline and fresh ice which clearly demonstrate that the sensors accurately measure ice stress. These sensors were chosen for this experiment because they can be easily installed in a small auger hole at essentially any depth in the ice and because their previous field performance had produced satisfactory results (Johnson and others, 1985). Hydraulic flatjack sensors were also employed on the experiment by other investigators (Coon and others, 1989). A comparison of stresses observed by the vibrating wire and flatjack sensors is the subject of an ongoing study.

Stress sensors were originally installed at four sites, two on Alpha floe and two on Beta floe (Fig. 2). In this paper, we present results from two sensors on Beta floe which were inside the strain triangle. One sensor was installed in new first-year ice, adjacent to the multi-year floe, which grew to a thickness of $0.50 \mathrm{~m}$ by the end of the experiment. The second sensor was placed in $2 \mathrm{~m}$ thick multi-year ice at a depth of $0.25 \mathrm{~m}$, a few meters from the edge of the floe. Data from the sensors were recorded at intervals of 1 or $2 \mathrm{~min}$ at each site using a data logging system. Also located at each stress sensor site were thermistor strings which were used to monitor ice temperature on an hourly basis and a few manually operated hot wire gauges for measuring thickness changes every 3-4 days.

\section{RESULTS AND DISCUSSION}

We have selected a period near the end of the drift for detailed examination. The period from 5 November (day $310)$ to 22 November (327) contained significant stress events that we believe are caused by different mechanisms. Figures $3 \mathrm{a}$ and $3 \mathrm{~b}$ show records of the principal stresses from the sensors in the lead ice and the multi-year ice on Beta floe for days 310 to 327 .

A brief comparison of the stresses from the two sensors
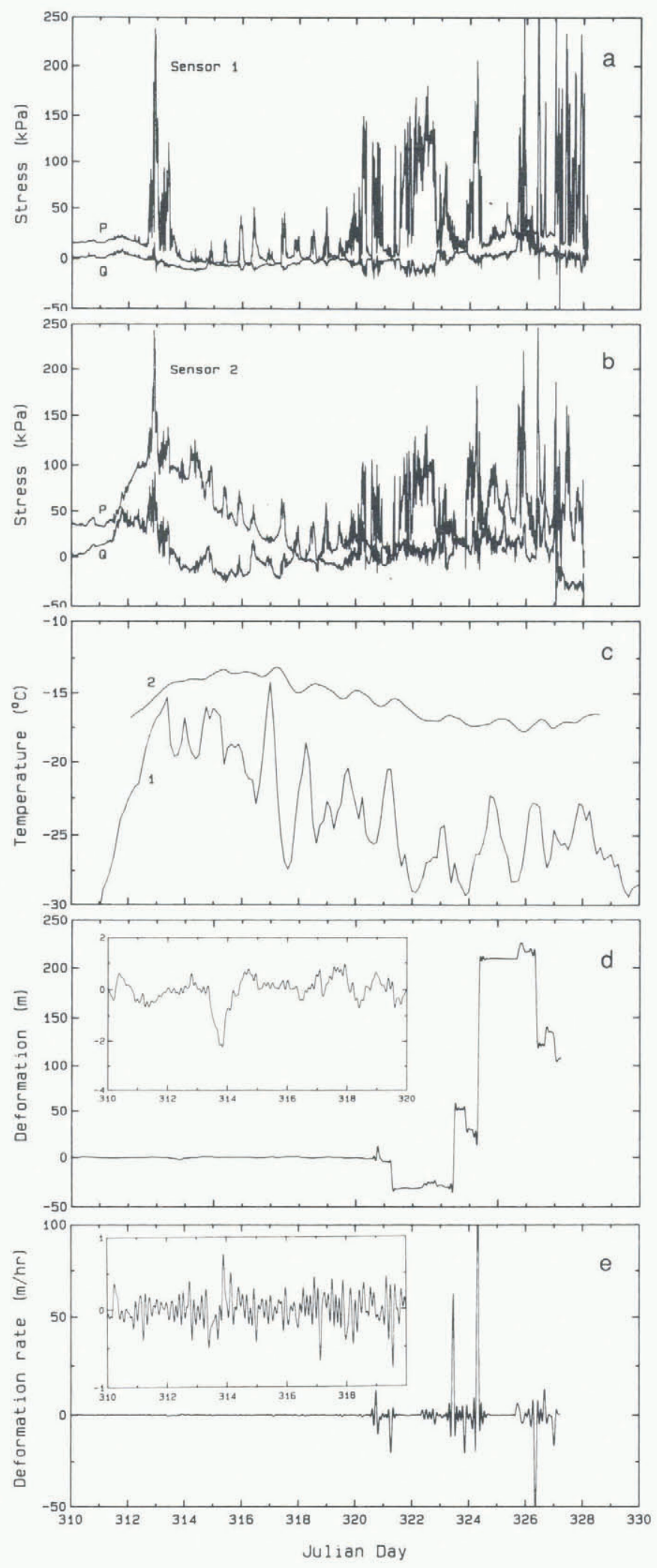

Fig. 3. Composite figure displaying results from day 310 to 330 for (a) stress at sensor 1, (b) stress at sensor 2, (c) air temperature (curve 1) and ice temperature at a depth of $0.2 \mathrm{~m}$ (curve 2), (d) deformation along leg 1 of the strain triangle and $(e)$ deformation rate along leg 1 of the strain triangle.

is worthwhile. Sensor 1, located at a depth of $0.25 \mathrm{~m}$ in first-year ice growing to $0.50 \mathrm{~m}$ thick, has a stress record that is distinct in character from the sensor in multi-year ice at the same depth a few meters away. There was a large event during day $312-313$, in which the peak stress 
was about $250 \mathrm{kPa}$. Following this event, beginning on day 315 , stress maxima of approximately $50 \mathrm{kPa}$ occurred regularly at $12 \mathrm{~h}$ intervals until day 320 . It is noteworthy that the $Q$-component of stress behaves contrary to the $P$ component for much of this period. That is, $Q$ is opposite to $P$ on some occasions, indicating a tendency towards tension when $P$ distinctly indicates compression. Sensor 2, located $2 \mathrm{~m}$ from the edge of the freezing lead on the multiyear floe, at a depth of $0.25 \mathrm{~m}$, has a completely different signature than sensor 1 before day 320 . The major feature is a long-term event which extends from day 311 to 317 . Superimposed on this is the large spike on days 312-313 which was the dominant feature in the record of sensor 1. The $12 \mathrm{~h}$ events are also apparent on sensor 2 . For this location, the $Q$-component of stress generally tracks the $P$ component; that is, compressive stresses in $P$ usually correspond to compressive, though reduced, stresses in $Q$.

We postulate that stresses caused by four distinct processes are evident in the stress sensor records: (1) stress from a single ridging event, (2) a $12 \mathrm{~h}$ periodicity due to tides or inertial oscillations, (3) thermally induced stresses and (4) stress resulting from the large-scale ridging associated with the disintegration of the ice cover. The first is an event such as pressure-ridging or shearing, in which stress is transmitted to the ice in which the sensor is installed. An example of this is the large spike which occurred on days $312-313$. This event was also observed on the transponder system (discussed later), in ambient noise records, in floe accelerometers and in stress sensors on Alpha floe. The second type of event is the approximately $12 \mathrm{~h}$ oscillations that are obvious on the records of both sensors between day 315 and 320 . A power spectrum analysis of sensor 1 stress data indicates significant power at a period of $12.3 \mathrm{~h}$ per cycle. We conjecture that these stresses are caused by the response of the ice to inertial or tidal forcing. McPhee (1990) clearly demonstrates inertial motions in the plotted positions of the ship during its drift. However, it was on day 315 that the drift took the ice onto the shallow $(200 \mathrm{~m})$ shelf surrounding Kvitøya, an island to the east of Svalbard. This suggests that tidal forcing may have caused the stresses.

The large long-term stress event beginning on day 311 and lasting until day 317 evident in the record of sensor 2 is probably thermally induced. Figure $3 \mathrm{c}$ shows the air temperature and the ice temperature at a depth of $0.20 \mathrm{~m}$ in the ice near sensor 2. The sensor 2 stress tracks the ice temperature nicely with the increase in air temperature and the warming of the ice causing an increase in compression. Since detailed laboratory calibrations have confirmed that the temperature sensitivity of the biaxial stress sensors is minimal, we are confident that the indicated stresses are those experienced by the ice at this location. Thermal stresses have been reported previously by Evans and Untersteiner (1971) and Milne (1972) from the standpoint that they may cause tension cracking in the ice. Milne (1972) and Lewis and Denner (1988) have both speculated that a significant amount of ambient noise may be generated by failure of the ice resulting from the thermally induced stresses. While the stresses induced by warming or cooling of the sheet are difficult to model because of the lack of understanding of the ice rheology and the large variations in ice properties, they can be conceptually described. Horizontal stresses are induced by the tendency of the ice to contract or expand with temperature. However, since rapid changes in air temperature are quickly attenuated with depth in the ice, only the upper tens of centimeters will experience the changes. These layers attempt to contract or expand with temperature, but since the deeper ice remains fixed, the ice attempts to bend or curl. It is prevented from bending by gravitational and buoyant forces; thus stresses are induced, particularly on the surface of the ice. The near-surface ice, therefore, should experience compressive stresses with warming and tensile stresses with cooling. This is an extremely simplistic explanation and is certainly complicated by such factors as the ability of the ice to creep and restore itself to a zero-stress state, the size of the floe, and the variations in ice properties.

We believe the above explanation of the large longterm stress to be plausible and responsible for the event observed on the sensor 2 record between days 312 and 317. It is particularly interesting that this event is not observed in the record of the sensor located in the thin first-year ice. Instantaneous thermal stresses (no creep) are the product of the elastic modulus, the coefficient of thermal expansion of sea ice and the temperature change (Evans and Untersteiner, 1971; Milne, 1972). Being warmer and more saline, the modulus of first-year ice is so small that the stress will not be significant. In addition, because the ice is more saline, it can be expected to creep at a higher rate than the multi-year ice, thus relieving the thermal stresses.

There was considerable dynamic activity in the area from day 320 to 327 as is shown in both the stress and the deformation records. Variations in stress peaked on days $326-327$, exceeding $250 \mathrm{kPa}$ in the lead ice and $200 \mathrm{kPa}$ in the multi-year ice. These stresses corresponded to large deformation and the destruction of the local ice cover.

The deformation along the short leg of the strain triangle (bold line on Fig. 2) is shown in Figure 3d. Since the large deformation after day 320 dwarfed the earlier activity, results from prior to day 320 are plotted on an expanded vertical scale as an insert. Negative values of deformation indicate convergence, whereas positive values indicate divergence. The deformation rate is plotted in Figure $3 \mathrm{e}$, again with the $310-230 \mathrm{~d}$ period plotted as an insert on an expanded scale. Both time series are smoothed by low-pass filtering at a frequency of $8 \mathrm{~d}^{-1}$. The deformation data show an abrupt convergence of about $2 \mathrm{~m}$ on day 313 , which roughly coincides with the end of a local maximum in both stress records. This abrupt convergence was present in all of the measured lines of deformation. Buckling at the intersection of Alpha and Beta floes was noted during field observations made at the time. The breakup of the multi-year floes in the local pack, caused by proximity to the island of Kvitøya and a steady onshore wind, began on day 320. The large abrupt deformations and the coincident high velocities shown in Figures $3 \mathrm{~d}$ and $3 \mathrm{e}$, in the period following day 320 , were shear deformations along lines which ran between the ship and Beta floe. These were very dramatic events, visible in the ship's spotlights, in which large shear ridges consisting of $2 \mathrm{~m}$ thick blocks of multi-year rubble were built.

A visual comparison of the stress and deformation signals shows few points of similarity besides the event of day 313 and the increase in the intensity in both datasets 
following day 320 . Therefore, in order to compare the stress and deformation data, we filtered the first-year ice stress data and the deformation data by passing each set of data through a series of bandpass filters. The filters, which were designed using the recipe given by Hibler (1972), had a bandwidth of $\pm 0.5 \mathrm{~d}^{-1}$ about the center frequency. The bandpass filtered stress and deformation datasets were cross-correlated and the average power in each sample was calculated. These results are presented in Table 1. In addition to showing results for the entire time period, the data have been partitioned into sub-intervals of days 310317 and 317-324. There was very little deformation during the first period, whereas the major strain events accompanying breakup occurred during the second. The error estimates assume that the data are uncorrelated white noise. The cross-correlation values, which are also plotted in Figure 4, are the maximum found in each frequency interval. Accompanying the cross-correlation values in Table 1 are the phase lags (or leads) for the peak values. By examination of the phase, it can be ascertained whether deformation leads stress, or vice versa.

The cross-correlation values for the total interval are largest at frequencies of 1 and $2.5 \mathrm{~d}^{-1}$, with the deformation generally leading the stress. The power spectra for stress, deformation and deformation rate (Table 1) show peaks at approximately 1 and $2 \mathrm{~d}^{-1}$. The data in Figure 4 suggest that the cross-correlation for the entire time period is dominated by the large events occurring during the second sub-interval (days 317-324), in that peak values occur at the same frequencies. This is also manifested in

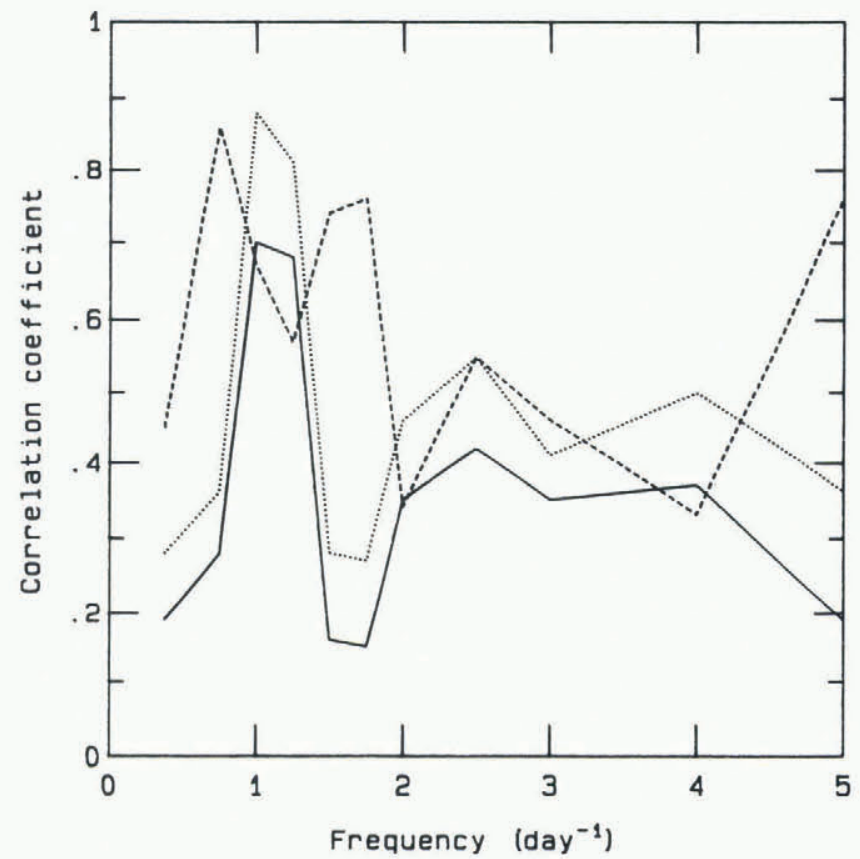

Fig. 4. Cross-correlation of first-year stress versus deformation for (1) days 310-324 (solid line), (2) days 310-317 (dashed line) and (3) days 317-324 (dotted line).

Table 1 where the phase lags of the correlation values for the entire interval are almost identical to those of the second sub-interval. In the first sub-interval (days 310317) where ice deformations are extremely small, the

Table 1. Normalized power as a function of frequency for stress in the first-year ice (NP-S), deformation $(\mathcal{N} P-D)$ and deformation rate $(\mathcal{N} P-D R)$. Frequencies are center band values with band widths $\pm 0.5 d^{-1}$. The bands overlap somewhat, thus the sum of the power in each band may exceed the total power. Peak correlation coefficients ( $C_{\max }$ ) and phase lag for first-year ice stress and deformation are presented for the entire period and for two sub-intervals. Positive phase lag corresponds to deformation leading stress. Errors in the correlation coefficients are \pm 0.2 for the entire period and \pm 0.3 for the sub-intervals

Deformation versus stress

Days 310-324 Days 310-317 Days 317-324

\begin{tabular}{rrrrrrrrrr} 
Freq & NP-S & NP-D & NP-DR & $C_{\max }$ Phase & $C_{\max }$ & Phase & $C_{\max }$ & Phase \\
\hline & & & & & & & & & \\
\hline 0.75 & 0.723 & 0.180 & 0.362 & 0.19 & 0.92 & 0.45 & -0.39 & 0.28 & 1.32 \\
0.75 & 0.104 & 0.180 & 0.081 & 0.28 & 0.07 & 0.86 & -0.67 & 0.36 & 0.07 \\
1.00 & 0.039 & 0.266 & 0.195 & 0.70 & 0.15 & 0.67 & 0.25 & 0.88 & 0.15 \\
1.25 & 0.069 & 0.195 & 0.200 & 0.68 & 0.08 & 0.57 & 0.00 & 0.81 & 0.08 \\
1.50 & 0.029 & 0.059 & 0.081 & 0.16 & 0.00 & 0.74 & -0.20 & 0.28 & 0.00 \\
1.75 & 0.053 & 0.010 & 0.022 & 0.15 & 0.00 & 0.76 & -0.26 & 0.27 & 0.00 \\
2.00 & 0.060 & 0.025 & 0.092 & 0.35 & -0.13 & 0.34 & 0.20 & 0.46 & -0.13 \\
2.50 & 0.024 & 0.024 & 0.124 & 0.42 & 0.04 & 0.55 & -0.12 & 0.55 & 0.04 \\
3.00 & 0.016 & 0.008 & 0.070 & 0.35 & -0.03 & 0.46 & -0.15 & 0.41 & -0.03 \\
4.00 & 0.010 & 0.001 & 0.022 & 0.37 & -0.01 & 0.33 & 0.08 & 0.50 & -0.01 \\
5.00 & 0.003 & 0.002 & 0.038 & 0.19 & 0.06 & 0.76 & -0.07 & 0.36 & 0.06 \\
\hline
\end{tabular}


cross-correlations are higher over a broad range of frequencies from 0.75 to $1.75 \mathrm{~d}^{-1}$, with stress, in general, leading deformation. This was reversed in the second subinterval, with deformation leading stress. These phase lags are consistent with the hypothesis that temperature was driving the stress in the first interval, and the proximity to Kvitøya was driving the deformation and the stress in the second interval. Although the correlation coefficients are reasonably large for certain cases, it must be kept in mind that they occur only for discrete frequency bands. Also, these correlations were obtained between stresses measured at one site and deformation along a single line rather than from a strain field.

In summary, the stress record indicates significant thermally-induced stresses in multi-year ice, periodic changes in stress due to tidal or inertial oscillations in both multi-year and first-year ice, and increased stress during the breakup of the ice cover with maximum compressive stresses of roughly $250 \mathrm{kPa}$. For much of the experiment ice deformations were small, on the order of meters, but they increased sharply to values of hundreds of meters during breakup. Qualitatively, we have determined that changes in stress lagged deformation during breakup. However, a rigorous relationship between stress and deformation has proved elusive. We hope to clarify this relationship in the future by using more transponders and stress sensors, and by improved positioning of the units.

\section{REFERENCES}

Comfort, G. and R. Ritch. 1990. Field measurement of pack ice stresses. In Ayorinde, O.A., N.K. Sinha, and D.S. Sodhi, eds. Proceedings of the Ninth International Conference on Offshore Mechanics and Arctic Engineering 1990 - presented at ... Houston, Texas, February 18-23, 1990. Vol. 4. Arctic/polar technology. New York, American Society of Mechanical Engineers, 177-181.

Coon, M.D., P.A. Lau, S.H. Bailey, and B.J. Taylor. 1989. Observations of ice floe stress in the eastern Arctic. In Axelsson, K.B.E. and L.A. Fransson, eds. POAC 89. The 10th International Conference on Port and Ocean Engineering under Arctic Conditions, June 12-16 1989, Lulea, Sweden. Proceedings. Vol. 1. Luleå, Tekniska Högskolan i Luleå, 44-53.

Cox, G.F.N. and J.B. Johnson. 1983. Stress measurements in ice. CRREL Rep. 83-23.

Croasdale, K.R., G. Comfort, R.M.W. Frederking, B.W. Graham, and E.L. Lewis. 1988. A pilot experiment to measure Arctic pack ice driving forces. In Sackinger, W.M. and M.O. Jeffries, eds. Port and Ocean Engineering under Arctic Conditions. Vol. 3. Fairbanks, AK, University of Alaska, Fairbanks. Geophysical Institute, 381-395.

Evans, R.J. and N. Untersteiner. 1971. Thermal cracks in floating ice sheets. F. Geophys. Res., 76(3), 694-703.

Frederking, R.M.W. and E. Evgin. 1990. Analysis of stress distributions in an ice floe. In Ayorinde, O.A., N.K. Sinha, and D.S. Sodhi, eds. Proceedings of the Ninth International Conference on Offshore Mechanics and Arctic Engineering - 1990 - presented at ... Houston, Texas, February 18-23, 1990. Vol. 4. Arctic/polar technology. New York, American Society of Mechanical Engineers, 8387.

Graham, B.W., L.G. Chabot, and G.R. Pilkington. 1983. Ice load sensors for offshore Arctic structures. Proceedings of the Seventh International Conference on Port and Ocean Engineering under Arctic Conditions, Helsinki, Finland, 5-9 April 1983. Vol. 4. Espoo, Technical Research Center of Finland, 547-562.

Hawkins, J.R., D.A. James, and C.Y. Der. 1983. Design, construction and installation of a system to measure environmental forces on a caisson retained island. Proceedings of the Seventh International Conference on Port and Ocean Engineering under Arctic Conditions, Helsinki, Finland, 5-9 April 1983. Vol. 4. Espoo, Technical Research Center of Finland, 770-779.

Hibler, W.D., III. 1972. Design and maximum error estimation for small error low pass filters. CRREL Res. Rep. 304.

Johnson, J.B., G.F.N. Cox, and W.B. Tucker, III. 1985. Kadluk ice stress measurement program. POAC 85. The 8th International Conference on Port and Ocean Engineering under Arctic Conditions, Narssarssuaq, Greenland, September 714, 1985. Proceedings. Vol. 1. Horsholm, Danish Hydraulic Institute, 88-100.

Leppäranta, M. and W.D. Hibler, III. 1987. Mesoscale sea ice deformation in the East Greenland marginal ice zone. J. Geophys. Res., 92(C7), 7060-7070.

Lewis, J.K. and W.W. Denner. 1988. Higher frequency ambient noise in the Arctic Ocean. 7. Acoust. Soc. Am., 84(4), 1444-1455.

McPhee, M.G. Unpublished. CEAREX 1988 Polarbjorn drift: position and velocity analysis. Report to Office of Naval Research, Arlington, VA.

Milne, A.R. 1972. Thermal tension cracking in sea ice: a source of underice noise. J. Geophys. Res., 77(12), 21772192.

Tucker, W.B., III, W.F. Weeks, A. Kovacs, and A.J. Gow. 1980. Nearshore ice motion at Prudhoe Bay, Alaska. In Pritchard, R.S., ed. Sea ice processes and models. Seattle, WA, University of Washington Press, 261-272.

The accuracy of references in the text and in this list is the responsibility of the authors, to whom queries should be addressed. 